\title{
Return On Marketing Investment Driven Sponsorship: Optimizing This Marketing Investment In Latin America
}

Nico Schinagl Waller, (E-mail: nico@ sforce.com.mx), Universidad Anáhuac del Sur, Mexico

\begin{abstract}
Marketing campaigns and strategies: We are all constantly exposed to their bombardment in our every day life, but few understand the undergoing revolution this field is experiencing to finally measure, in financial terms, its impact. Gone are the days of the creative marketing and to stay is the era of quantifiable marketing, a new stage in the field that simply wants to measure if the marketing effort has yielded an impact on what really counts: selling more, to more people, more often and at a higher margin. The following paper targets the sponsorship side of the marketing field, whether expos and trade shows, sponsorships of musical events, recreational gatherings, or company driven shows. Its objective is clear, in as to show a methodology that achieves a strategy to optimize this investment for consumer companies in Latin America. After a comprehensive market study, that analyzed the current measuring marketing methods in Mexico of over 70 marketing executives that manage over \$282 million dollars in yearly marketing budgets, the proposed methodology was successfully implemented during 2006 for Tequila Casa Cuervo in Mexico by the author. A case study will be presented at the end of this paper to provide a real life example.
\end{abstract}

\section{INTRODUCTION}

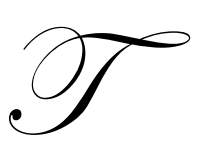

he main objective of this research is to present a method to optimize the marketing investment destined towards sponsorships and image accounts, an investment that is currently still viewed by $58.5 \%$ of executives as a cost rather than an investment that provides attractive returns.

The sponsorships side of marketing has undergone drastic changes in recent years, from being a simple part of the public relations effort of the company, to becoming a strategy with a new goal of establishing an emotional connection between the brand and the desired target market segment through sponsorship of social gatherings, entertainment and sporting events, and the presence at image accounts frequented by the desired customer base. ${ }^{1}$

Recommended to represent between 5 and 12 percent of the marketing budget of a consumer company ${ }^{2}$, it is not surprising that the Marketing Science Institute has established in its research guidelines between the period of $2004-2006$ as a top priority "identifying the metrics and relating the impacts of all marketing efforts and campaigns in financial terms." ${ }^{3}$ With the trend to measure return on marketing investment in full swing, the first inquiry was to determine the current marketing measurements used in Latin America, the extend this regional market had adopted

\footnotetext{
${ }^{1}$ Cf AMBLER, Tim. (2003) "Marketing and the Bottom Line". Second Edition. Prentice Hall. U.K.

${ }^{2}$ Rf FAIRCHILD, M. (2000). "The IPR Toolkit.” London: Instritute of Public Relations. U.K.

${ }^{3}$ Rf Marketing Science Institute. (2004). "Research Priorities 2004-2006”. www.msi.org.
} 
this shift in marketing metrics, and how a method could be successfully implemented for the region as a whole. Thus, a market study lay at hand. Table 1 illustrates the general dimensions this exploratory research held in Mexico had, as well as the nature of its participants.

Table 1

Initial Research Outline And Dimensions

January 2006

- \# of Participants - 70 executives

- Industries / Verticals - Consumer products $42.85 \%$, Consumer beverages $42.85 \%$, Pharmaceutical (OTC) $14.3 \%$

- $\quad$ Annual Marketing Budget - US\$282,000,000

- $\quad$ \# of Yearly Campaigns per executive - Average of 20 Campaigns

- $\quad$ Average Budget per executive interviewed - US\$4,028,571

- $\quad$ Positions held - Marketing Managers \& Brand Managers

- $\quad$ Time period - between June and December 2005

Some of the key findings of the study were:

- $\quad$ Still a staggering $58.5 \%$ of the Mexican marketing executives felt their activities and campaigns were viewed as a cost for the company, rather than an investment.

- $\quad$ Compared to the U.S., were $68 \%$ of all marketing executives admitted not to be able to measure ROI metrics of all their marketing campaigns, in Mexico over $80 \%$ admitted the same, although the majority (57.2\%) mentioned they had all the necessary information.

- Meanwhile, $67.1 \%$ admitted only to be able to measure return on investments of $10 \%$ of their yearly campaigns, thus resulting for the sample an amount of US\$170 million of unjustified marketing expenditure.

- $\quad 65.7 \%$ of the executives mentioned their marketing budget was derived from an overall or global budget, with little input on their behalf.

- When asked which were their key motivator to change their yearly marketing budget allocation, $74.2 \%$ replied the discrepancy between the desired forecast and actual sales results, while $18.5 \%$ mentioned it was because of campaigns or actions by close competitors.

- $\quad$ Other interesting results from the study, was that $80 \%$ of the marketing executives in Mexico still found the open television as the mass media with more impact compared to $18 \%$ in the U.S. as per a study by the Marketing Science Institute.

After the market study, it was obvious that the trend in marketing to justify its investment via financial ROI metrics was still in its initial stages in Mexico and it could be assumed, in the rest of Latin American region.

\section{METHODOLOGY}

The real challenge of the proposed method was to identify a measuring metric that allowed for different campaigns to be compared, as to offer a tool to optimize the investment at hand. Since sales figures in most cases could not be justified as a direct result of the campaigns, another common denominator had to be established.

In expos or trade show participations, where the objective is to generate pre-validated prospects for the sales force, this poses little challenge, although few companies really measure the Return On Marketing Investment (ROMI) of these kinds of investments. Table 2 shows a quick overview of the most frequently used metrics, the cost 
per win being the main success indicator, allowing differently attended trade shows with different investments, to be compared easily.

Table 2

Initial Research Outline And Dimensions

January 2006

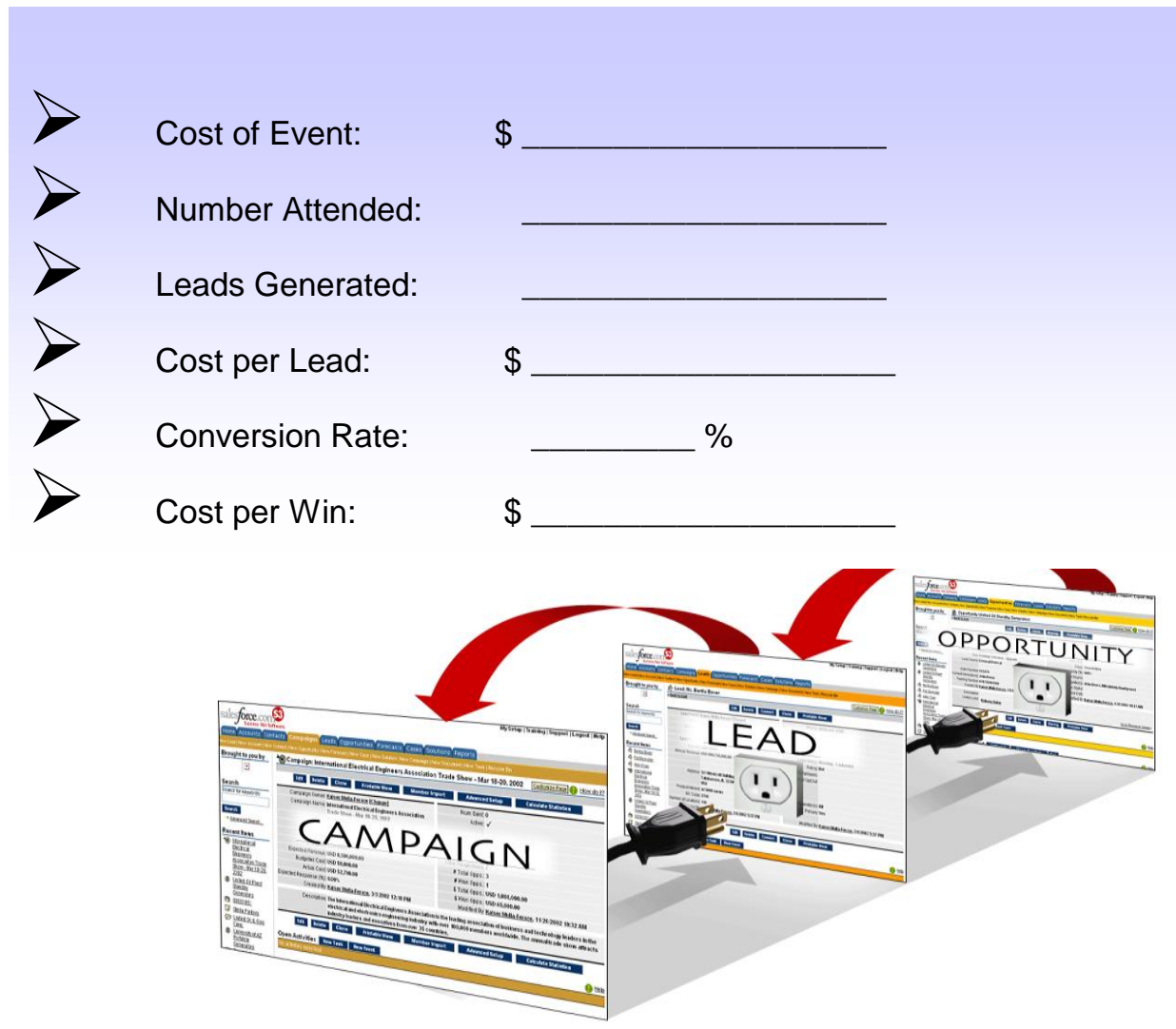

Of course, with other sponsorships where the sales results can not be tracked so easily to a single event (also called the origin of the opportunity), the situation changes. With sponsorships of events (Table 3 shows how the Coca-Cola Company segments its sponsorships) it is necessary to divide into two separate categories:

- $\quad$ Events only image related.

- $\quad$ Events not only image related, but where on-premise sales can be achieved.

\section{Image Events}

Defined as sponsorships in which there are no related product sales, or implied concessions to achieve those sales. A music concert, for example, since the attending public is exposed to the brands image, but there are no sales directly related by the event. In these cases, the method proposes a simple scoreboard that allows identifying the attractiveness of the event, by evaluating common denominator success metrics, which include:

\section{- $\quad$ Cost per Impact}

Result of Investment / Total Attendants helping compare events with different foot traffic and different 
required investments.

- $\quad$ Fit with Target Segment

Ranks the event with regards to its fit between the people attending the event and the desired target segment of the brand.

- Number of Sponsorships

Grades the event with regards to the number of other sponsorships present, ranking the event with fewer additional sponsors better than the event clogged with numerous sponsors.

Table 3

Event Segmentation

January 2006

\section{Cultural Centers}

Shopping Centers

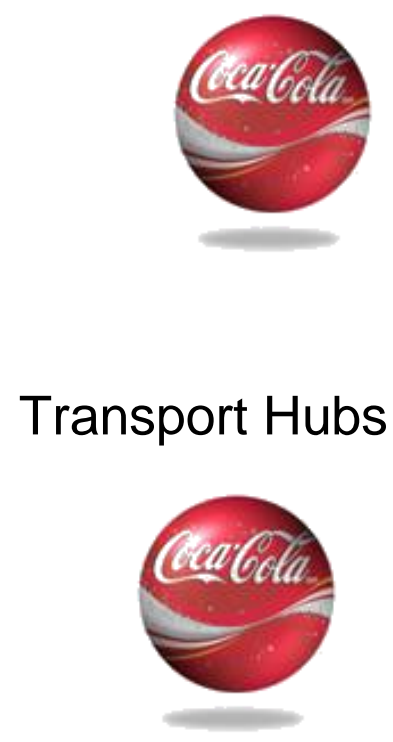

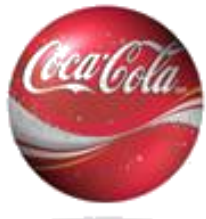

Sporting Events

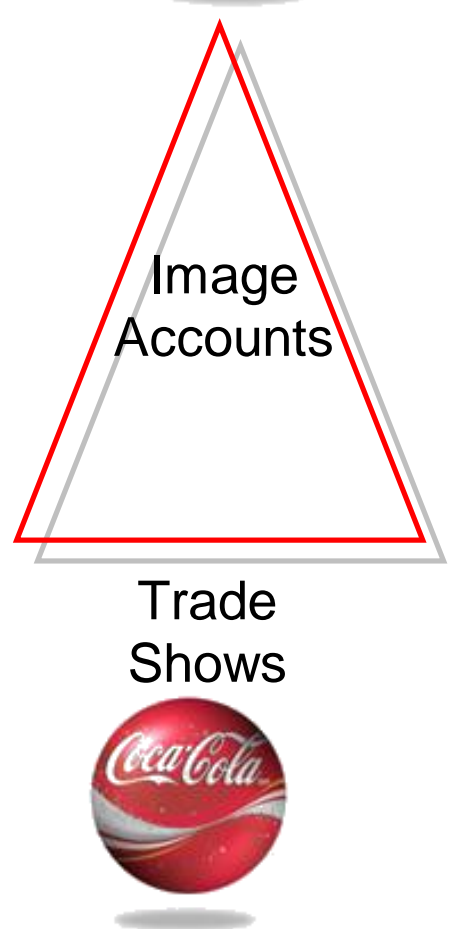

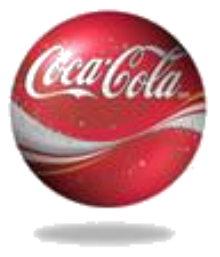

Amusement Parks

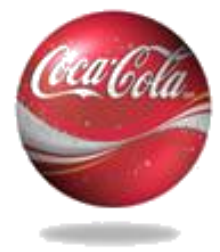




\section{Image Event With Sales}

Defined as sponsorships, in which not only exposure of the brand can be gained, but also product sales can be generated and directly related to the event. Corporate sponsorships of amusement parks is only one of many examples, but shows that not only is image exposure gained, but also all product sales concessions are part or included in the sponsorship agreement.

Thus besides the above mentioned scoreboard, another metric can be inserted, depending on the selling unit of the customer.

\section{- $\quad$ Cost Per Unit Sold}

Being the result of the total investment into the account / unit sold that can be directly related to the sponsorship in a given time period.

This method also applies to the different strategies used by consumer companies at the point of consumptions, such as nightclubs, bars and restaurants, where the investment is not only positioned in image related items, but also in the training, compensation and sales competitions among the service staff, which often function as an extension of the sales forces of the brand.

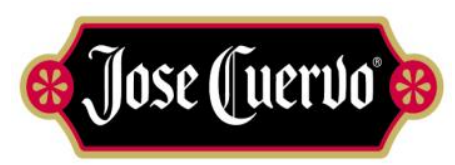

\section{Case Study: Casa Cuervo S.A. De C.V.}

The World-renowned Tequila Cuervo, proudly belongs to a Mexican company, Casa Cuervo, a company not only dedicated to the manufacturing, distribution, and sales of its own Tequila brand, but also a distributor in Mexico of world-class brands such as Absolut, Jagermeister, to mention a few.

Currently at number two in total sales, only behind the Bacardi Company, it is aggressively aiming at the number one spot. To achieve this success, besides heavily investing in advertising, seeking new trendy products to distribute, Casa Cuervo also has established a strategic presence at the point of consumption (bars, nightclubs, restaurants, etc..) also know as the on-premise market in the main cities of Mexico, as well as the main tourist beach resorts all over the country.

With a sales force of 46 executives, handling over 900 establishments, the strategy resonated through the Mexican beverage industry, gaining good acceptance from the consumer, and coming up with such incentive programs as "Club Conexión", a measure to compensate waiters for actively promoting and selling the companies brands.

Although the investment in each establishment was closely counted, and sales per case were being tracked, the company had not made the connection to identify and measure the total impact of the strategy. It was widely believed, that the brands presence at the point of consumption, was there to drive sales in the retail or home market, by creating consumption habits and top of mind in the consumer. Thus, no real attempt had been made to measure the ROMI metrics.

But the arrival of a new director modified this soft metrics approach, and in a workshop (lead by the author) 
held in January 2006 for the first time, the real return every establishment was measured. The starting block was to be the assigned customer listing of each individual sales executive (averaging between 18 and 25 establishments) to identify the top customers, their mid market and their smaller accounts (see Table 4).

A good starting point for the analysis, but without any real use, due to the sales oriented tracking and the lack of return on investment metrics. Thus, the metrics of the proposed method were included, providing dimension to the analysis, by identifying the cost per impact and cost per case sold by each establishment.

A historical data base was created, that illustrated the sales in cases per each establishment during the year 2005, as well as the average monthly foot traffic registered in each of these bars, nightclubs or restaurants.

Resulting fact: in 2005 only a 4.3\% ROMI had been achieved, since the cost per case sold had been only marginally lower than the profit margin per case. Obviously, for 2006, the aim was to increase the return on investment, and being the first year, the goal was to more than double it to $10 \%$ total.

Another side analysis complemented this strategic goal, identifying the profit margin by type of product sold, and unifying the measuring metrics (cases) to 9 liter cases (some products were being sold in different size cases, and to be able to compare all sales and products, a median measurement was established).

Table 4

Same Customer Listing Segmentation

January 2006

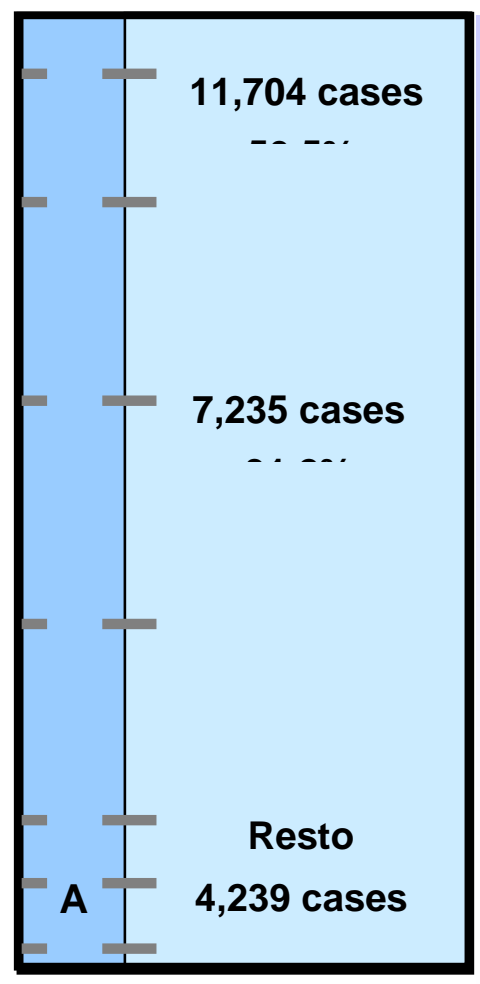

rocac Cnld. 22178 nocac
Top 3 Accounts: Platinum Partners

Average Cases: $\quad 3,901$

Estrategias:

Top 5 Accounts: Gold Customers

Average Cases: $\quad 1,447$ 
By implementing the following actions and strategies, the aggressive goal was to be achieved:

- $\quad$ Each sales executive had to list his or hers three worst producing establishments in terms of cost per case sold (in some cases over 4 times the average profit margin) to be eliminated.

- $\quad$ Propose accounts and establishments in each sales territory, which could provide better return on investment metrics, based on their consumption (in cases) and foot traffic.

- Limit investment thresholds with the new desired success metric of $10 \%$ ROMI for the fiscal year in not extremely image oriented establishments, optimizing the overall investment.

- $\quad$ Pushing product related promotions in image accounts that were below the desired success metric.

- Inform key customers of the change in sponsorship policy, illustrating and explaining metrics to the owners and/or management of the establishments.

\section{RESULTS}

Although the main selling season for Casa Cuervo was still around the corner (between September through December over 55\% of all company sales are achieved), the cleansing of the customer listing, and the focus on the return on investment, had already shown a profound impact over the efficiency of the operation, ending Q1/06 with a $7.9 \%$ ROMI vs. the overall $4.3 \%$ ROMI achieved in 2005 .

NOTES 


\section{NOTES}

